\title{
EVOLUÇÃO GEOGRÁFICA DO USO/COBERTURA DA TERRA NA BACIA DO RIO VIEIRA NO NORTE DE MINAS GERAIS
}

\author{
Jorge Luis Brito ${ }^{1}$ \\ Monoel Reinaldo Leite ${ }^{2}$ \\ Expedito Jose Ferreira ${ }^{3}$ \\ Marcos Esdras Leite ${ }^{4}$
}

Resumo: O mapeamento temporal do uso/cobertura da terra permite obter dados sobre a dinâmica de mudança do espaço natural, consequentemente essas informações poderão auxiliar na análise da transformação ambiental. Nesse contexto, este trabalho procurou analisar as mudanças no uso/cobertura da terra da bacia do Rio Vieira, nos últimos 25 anos, cujos períodos de análise definidos foram 1985, 1995 e 2010. Do ponto de vista operacional, o tempo de execução da metodologia utilizada, desde a aquisição dos produtos orbitais até a validação dos mapeamentos, foi relativamente curto. Fato que merece destaque, sobretudo, porque permitiu a elaboração de uma vasta gama de informações temporais da bacia do Rio Vieira. Destacando uma recuperação de 54,79 $\mathrm{km}^{2}$ de vegetação natural.

Palavras-chave: Mapeamento, Uso/Cobertura da Terra e Bacia do Rio Vieira.

\section{Geographical Evolution of Land Use/Cover in River Basin Vieira in Northern of Minas Gerais}

Abstract: The temporal mapping of land use/cover permits to obtain data on the dynamics of change of the countryside, therefore such information may assist in the analysis of environmental change. In this context, this study sought to analyze the changes in land use/cover in the basin of the Rio Vieira, the last 25 years, whose analysis periods were defined in 1985, 1995 and 2010. From an operational standpoint, the runtime of the methodology used, since the acquisition of the orbital products to validate the mappings, was relatively short. Fact that deserves attention, especially because it allowed the development of a wide range of temporal information River basin Vieira. Highlighting a recovery of $54.79 \mathrm{~km}^{2}$ of natural vegetation.

Keywords: Mapping, Land Use/Cover and River Basin Vieira.

\section{INTRODUÇÃO}

O mapeamento por imagem de satélite é uma fonte importante de dados sobre o tipo e a dinâmica da ocupação da superfície terrestre. As informações do uso da terra são imprescindíveis para o planejamento territorial e ambiental, pois são basilares para o processo de conhecimento da organização do espaço (TENDEDÓRIO, 1989).

\footnotetext{
${ }^{1}$ Professor Doutor da Universidade Federal de Uberlândia-UFU. E-mail: jbrito@ufu.br

${ }^{2}$ Pesquisador mestre da UNIMONTES. E-mail: manoelreinaldo@ig.com.br

${ }^{3}$ Professor Doutor UNIMONTES. E-mail: expedito.ferreira@unimontes.br

${ }^{4}$ Professor Doutor UNIMONTES. E-mail: marcosesdras@ig.com.br DOI: 10.7154/RDG.2013.0026.0009
} 
No entanto, no processo de mapeamento da dinâmica do uso da terra é recomendado que se estabeleça a diferença entre as terminologias uso da terra e cobertura da terra. Turner et al. (1995) afirmou que a cobertura da terra é o estado biofísico imediato da superfície da terra e da subsuperfície, ou seja, trata do tipo de objeto que cobre a superfície num dado momento. Enquanto que o uso da terra envolve a maneira pela qual os atributos biofísicos da terra são manipulados e a intenção relacionada a essa manipulação, isto é, a finalidade para a qual é usada a terra.

Essa definição é semelhante a da Organização das Nações Unidas para a Agricultura e Alimentação (FAO, 1995) que trata o uso do solo pelo critério funcional, assim, entende que o conceito de uso está relacionado à finalidade para a qual a terra é usada pela população.

Portanto, pela imagem de satélite obtém-se a resposta espectral da cobertura do solo e através da cognição humana pode-se defnir qual é o uso. Por isso, para se chegar ao mapa do uso do solo é imprescindivel identificar a cobertura da terra.

No processo de classificação de imagem de satélite é comum identificar tanto classe de cobertura, quanto de uso, por isso, na literatura específica de mapeamento de mudança da paisagem, por produtos orbitais, é usual o termo classes de Uso/Cobertura da terra.

Portanto, entende neste trabalho que a expressão "uso/cobertura da terra" denota atividades humanas de ocupação e exploração da superfície do planeta e dos seus recursos em função da necessidade de manutenção das sociedades humanas. Além disso, contempla a cobertura natural da terra, uma vez que essa é usada como reserva para exploração ou mesmo para conservação ambiental.

Dentro dessa ótica, Silva (1995) argumenta que, até por volta da década de 1960, a terminologia "uso da terra" não fazia nenhuma menção às questões ambientais e sobre os impactos desse "uso" no revestimento natural dos solos e as consequências de sua substituição. Essa terminologia refletia a intenção de promover a classificação dos espaços naturais de modo a identificá-los para facilitar seu reconhecimento e exploração.

O IBGE (2006) entende que o trabalho da Comissão Mista para Informação e Classificação do Uso da Terra de 1971 foi um marco teórico na compreensão dos estudos envolvendo a terminologia "uso da terra". Principalmente porque para a Comissão os estudos envolvendo o uso da terra passaram a considerar o revestimento dos solos e efetivamente a questão ambiental. Enfatizando a interdependência entre esses componentes e a necessidade de planejamento dos usos da terra. 
Ainda conforme IBGE (2006), a consolidação de um novo marco surge quando do avanço tecnológico dos meios de observação do planeta. Somados à facilidade de obtenção de imagens da superfície possibilitadas pelos dispositivos imageadores.

A mescla entre as novas concepções teóricas oriundas dos trabalhos da comissão e dos avanços tecnológicos de observação da Terra definitivamente descreve um novo marco teórico-metodológico para os estudos sobre o uso/cobertura da terra. Já que permite a fundamentação de metodologias calcadas nas perspectivas teóricas que orientam os estudos sobre o uso do território visando à justiça socioambiental. Principalmente, considerando o fato de que o uso/cobertura da terra implica em atividades humanas destinadas à obtenção de produtos e benefícios, a partir da transformação do espaço natural, e deve, portanto, ser entendido como sinônimo de espaço geográfico, tendo em vista a dinâmica do uso do território.

Assim sendo, os estudos sobre o uso/cobertura da terra devem contemplar as variações no espaço-tempo por força das mudanças de orientações que norteiam a utilização dos espaços em diferentes momentos. Isso é a dinâmica imposta pelos ciclos econômicos sobre o uso/cobertura das terras impõe uma variação nestes ambientes ao longo do tempo, com consequências para o espaço físico, ou seja, áreas que em determinados períodos eram destinadas à produção podem ser, em outros períodos, abandonadas, de forma que o contrário também pode ser verdadeiro.

Diante desta realidade, o sensoriamento remoto se destaca como uma ferramenta de importância singular, já que os dados de sensor remoto vêm dando suporte a vários estudos sobre a superfície da Terra, sobretudo quando se considera a possibilidade de obtenção de informações temporais como os dados da série TM - Landsat 5 , que se pontuam como uma importante fonte de informações históricas, permitindo o mapeamento e a quantificação de informações pretéritas e atuais das áreas imageadas.

Assim sendo, este trabalho se norteia pela seguinte indagação: qual é a dinâmica geográfica de ocupação e utilização das terras da Bacia do Rio Vieira imposta pela ocupação humana ao longo dos anos de 1985, 1995 e 2010. Direcionado por essa indagação, este trabalho procurou analisar, com auxílio de dados TM - Landsat 5, as mudanças e seus motivos no uso/cobertura da terra da bacia do Rio Vieira nos últimos 25 anos.

A escolha da bacia do Rio Vieira se justifica pelo fato de que esta área foi palco de um rápido e intenso crescimento populacional. De forma que essa realidade proporcionou várias 
modificações nos sistemas de uso/cobertura da terra desta bacia, como por exemplo: rápida expansão urbana, recuperação de áreas antropizadas e a antropização de áreas naturais. Permitindo, neste contexto, o desenvolvimento deste trabalho num ambiente com as devidas alterações dos sistemas de uso/cobertura da terra.

Dentro desta perspectiva, analisar a ocupação e utilização geográfica das terras da Bacia do Rio Vieira, a partir da série histórica do TM - Landsat 5 é de singular relevância para a compreensão dos impactos ambientais acarretados pelas intervenções humanas neste ambiente. Permitindo compreender os mecanismos que permitiram a atual configuração dos sistemas de uso/cobertura da terra nesta bacia.

\section{MATERIAIS E MÉTODOS}

\section{Localização da área de estudo}

A bacia do Rio Vieira está localizada no Norte do estado de Minas Gerais, totalmente inserida dentro dos limites do município de Montes Claros, como ilustra a Figura 01, ocupando uma área de $578,31 \mathrm{~km}^{2}$, ou $16,20 \%$ das terras do município, locadas, especificamente, no polígono formado pelas coordenadas 16 $32^{\prime} 53^{\prime \prime}$ e 16 $51^{\prime} 26^{\prime \prime}$ de latitude Sul e 43 44' 05"' e 44ㅇ 03' 40" de longitude Oeste.

O perímetro urbano do município de Montes Claros ocupa 15,8\% da área da bacia, o qual, conforme destacam os dados do censo de 2010 do IBGE, abriga uma população de 344.479 habitantes, apontando uma densidade demográfica de 3770,57 hab/ $\mathrm{km}^{2}$ (IBGE, 2011).

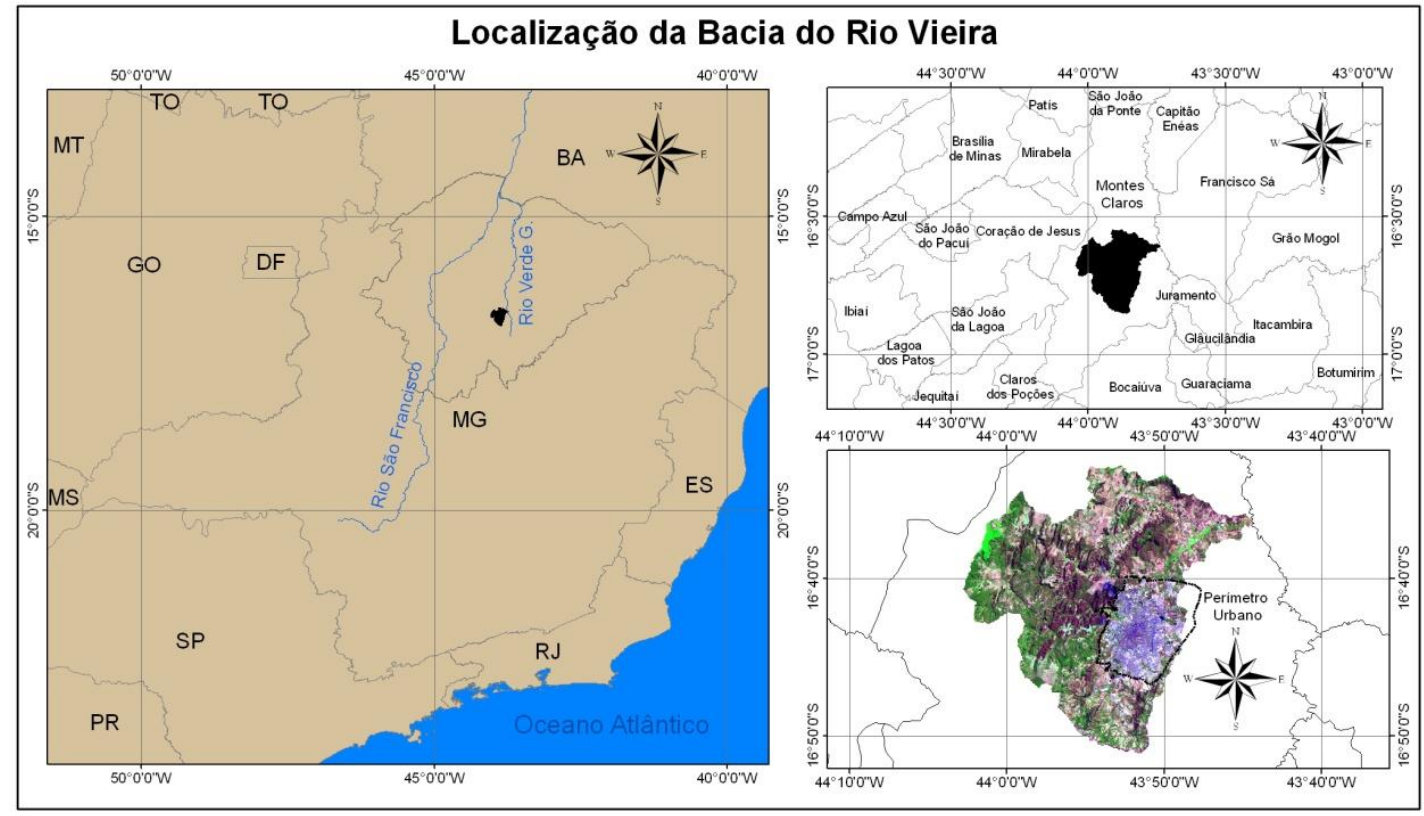

Figura 01 - Localização da Bacia do Rio Vieira. 


\section{Materiais e procedimentos técnicos operacionais}

Para a realização deste trabalho os seguintes materiais foram necessários:

$\checkmark$ Imagens do satélite Landsat 5, sensor Thematic Mapper (TM), órbita ponto 218 / 72, no formato digital de 28/08/1985, 09/09/1995 e 17/08/2010.

$\checkmark$ Imagens do modelo numérico de elevação oriundo do subsistema VNIR/ASTER, com resolução espacial de $30 \mathrm{~m}$, disponibilizadas no Site da NASA(http://asterweb.jpl.nasa.gov/gdem-wist.asp).

Disponibilizadas pelo Instituto Nacional de Pesquisas Espaciais, as imagens Landsat 5 - TM possuem nível básico de tratamento. Neste caso, houve a necessidade de correção e tratamento dessas imagens. As etapas executadas contemplaram os seguintes passos: correção atmosférica, correção geométrica e correção topográfica.

O modelo de correção atmosférica utilizado foi o desenvolvido por Chavez (1988). Para tanto foram computados os valores estatísticos de cada banda espectral das imagens Landsat 5 TM no intuito de montar a tabela 01, a qual contém os valores de níveis de cinza, de cada banda, para serem subtraídos.

Tabela 01 - níveis digitais escuros de referência para correção atmosférica

\begin{tabular}{|c|c|c|c|c|c|}
\hline Banda & ND & Banda & ND & Banda & ND \\
\hline \multicolumn{2}{|c|}{2010} & \multicolumn{2}{|c|}{1995} & \multicolumn{2}{|c|}{1985} \\
\hline B1 & 35 & B1 & 37 & B1 & 58 \\
\hline B2 & 15 & B2 & 12 & B2 & 31 \\
\hline B3 & 13 & B3 & 10 & B3 & 20 \\
\hline B4 & 5 & B4 & 4 & B4 & 15 \\
\hline B5 & 3 & B5 & 3 & B5 & 6 \\
\hline B7 & 0 & B7 & 1 & B7 & 0 \\
\hline
\end{tabular}

Posteriormente foi escrita a equação 01 , para a subtração dos valores de referência em cada banda de referência: ([B_referência]).

DkSB = ([B_referência] - Float(valor_escuro) $)$

01

O resultado desta expressão é uma imagem cujos valores de radiância de percurso foram suavizados, sobretudo para os alvos em que no nível do satélite não deveriam registrar valores de energia. 
No passo seguinte, as imagens foram registradas ao modelo numérico do terreno (MNT) através da extensão do ArcGis 9.3.1. Para tanto, foram criados os arquivos de Raster Dataset associados a 25 pontos de controle para cada imagem e coincidentes com o MNT/ASTER. Esse procedimento apresentou um erro quadrático médio de $8,45 \mathrm{~m}$, ou seja, menor do que $1 / 2$ pixel.

A necessidade de realizar a correção topográfica nas imagens advém do fato de que áreas sombreadas pelo relevo, após a correção atmosférica realizada anteriormente, apresentarem valores na ordem de zero. A execução dos cálculos para a correção topográfica implica na transformação dos níveis digitais das imagens, corrigidas na etapa anterior, em dados físicos de reflectância $(\lambda)$, conforme metodologia apresentada por Smith et. al. (1980).

Para esta conversão utilizou-se da equação 02 apresentada por Markham e Barker (1986), a qual converte os (NDs) de cada uma das bandas do Landsat 5 - TM em radiância espectral monocromática, que representa a energia solar refletida e a energia emitida pela superfície da Terra, de cada pixel, por unidade de tempo, de área, de ângulo sólido e de comprimento de onda medido ao nível do satélite.

$$
\mathrm{L}_{\lambda \mathrm{i}}=a_{i}+\frac{b_{i}-a_{i}}{255} \times N D
$$

Em que, $\alpha$ e b são radiâncias espectrais mínimas e máximas $\left(\mathrm{Wm}^{-2} \mathrm{sr}^{-1} \mu \mathrm{m}^{-1}\right)$, conforme tabela 02 e 03; ND são os níveis digitais de cada pixel da imagem variando de 0 a 255; e í são as bandas $(1,2,3,4,5,6$ e 7$)$ do satélite Landsat 5 - TM.

Para a obtenção da reflectância, que é a razão entre o fluxo de radiação solar refletido pela superfície e o fluxo de radiação global incidente, utilizou-se a equação (03) apresentada por Allen et. al. (2002).

$$
\rho_{\lambda i}=\frac{\pi \cdot L_{\lambda i}}{k_{\lambda i} \cdot \cos Z \cdot d_{r}}
$$

Em que, $L_{\lambda i}$ é a radiância espectral monocromática de cada banda do TM Landast $5, k_{\lambda i}$ é a irradiância espectral solar no topo da atmosfera de cada banda (tabela 02 e 03), $d_{r}$ é o inverso do quadrado da distância relativa Terra-Sol em unidades astronômicas de acordo com o dia do ano onde se considera a equação (04) apresentada por Duffie e Beckman 
(1980) e Z é o anglo zenital solar e pode ser obtido com o auxílio de MNT e a equação (05), proposta por Duffie e Beckman (1991),.

$d_{r}=1+0,033 \cos (2 \pi D D A / 365) \quad(04)$

Sendo que DDA é o dia do ano contado consecutivamente de 01 de janeiro até a data de passagem do sensor, considerando fevereiro com 28 dias.

$\operatorname{Cos} Z=\operatorname{sen}(\delta) \operatorname{sen}(\phi) \cos (s) \operatorname{sen}(\delta) \cos (\phi) \operatorname{sen}(s) \cos (\nu)+\cos (\delta) \cos (\phi) \cos (s) \cos (\omega)+\cos (\delta) \operatorname{sen}(\phi) \operatorname{sen}$ $(s) \cos (\gamma) \cos (\omega)+\cos (\delta) \operatorname{sen}(\gamma) \operatorname{sen}(s) \operatorname{sen}(\omega)$

Sendo que $\delta=$ declinação do Sol; $\phi=$ latitude do pixel (positiva no hemisfério Norte e negativa no hemisfério Sul); $s=$ inclinação da superfície, onde $s=0$ para superfície horizontal e $s=\pi / 2$ rad para inclinação vertical, $\gamma=$ ângulo do aspecto da superfície, onde $\gamma=0$ para inclinação orientada para sul, $\gamma=-\pi / 2$ rad para inclinação orientada para leste, $\gamma=+\pi / 2$ rad para inclinação voltada para oeste e $\psi= \pm \pi$ rad para inclinações orientadas para norte.

O parâmetro $\omega$ é o ângulo horário, com $\omega=0$ ao meio-dia solar, $\omega<0$ pela manhã e positivo à tarde.

Tabela 02 - Descrição, intervalo de comprimentos de onda e coeficientes de calibração, das bandas espectrais do Landsat 5, seguidos pelas radiâncias espectrais mínima (a) e máxima (b) e irradiância espectral no topo da atmosfera para imagens até 04/05/2003

\begin{tabular}{|c|c|c|c|c|}
\hline \multirow[t]{2}{*}{ Descrição dos canais } & \multirow[t]{2}{*}{ Comprimento de onda ( $\mu \mathrm{m})$} & \multicolumn{2}{|c|}{$\begin{array}{l}\text { Coeficiente de calibração } \\
\left(\mathrm{Wm}^{-2} \mathrm{sr}^{-1} \mu \mathrm{m}^{-1}\right)\end{array}$} & \multirow[t]{2}{*}{$\begin{array}{c}\text { Constante solar } \\
\left(\mathrm{Wm}^{-2} \mu \mathrm{m}^{-1}\right)\end{array}$} \\
\hline & & a & b & \\
\hline B 1 (azul) & $0,45-0,52$ & $-1,52$ & 152,0 & 1958,00 \\
\hline B 2 (verde) & $0,53-0,61$ & $-2,84$ & 296,81 & 1828,00 \\
\hline Banda 3 (vermelho) & $0,62-0,69$ & $-1,17$ & 204,3 & 1559,00 \\
\hline B 4 (infrav. próximo) & $0,78-0,90$ & $-1,51$ & 206,2 & 1045,00 \\
\hline B 5 (infrav. médio) & $1,57-1,78$ & $-0,37$ & 27,19 & 219,00 \\
\hline B 6 (infrav. termal) & $10,4-12,5$ & 1,2378 & 15,303 & - \\
\hline B 7 (infrav. médio) & $2,10-2,35$ & $-0,15$ & 14,38 & 75,00 \\
\hline
\end{tabular}

Fonte: Serviço Geológico dos Estados Unidos da América.

Para os cálculos de correção do efeito topográfico, para as imagens deste trabalho, considerou-se o fato de que a superfície reflete a radiação de uma forma isotrópica, em conformidade com o modelo de reflectância Lambertiano. Nesse modelo, as variações na reflectância são devidas à quantidade da radiação incidente, já que a iluminação de uma superfície é diretamente proporcional à intensidade luminosa da fonte na direção da superfície, portanto, proporcional ao cosseno do ângulo de incidência dos raios luminosos. 
Nesse caso, dada a normalidade da incidência da radiação, o recebimento de energia sofrerá a mesma variação que o cosseno do ângulo zenital, (SMITH et al. 1980).

Tabela 03 - Descrição, intervalo de comprimentos de onda e coeficientes de calibração, das bandas espectrais do Landsat 5, seguidos pelas radiâncias espectrais mínima (a) e máxima (b) e irradiância espectral no topo da atmosfera para imagens pós 04/05/2003

\begin{tabular}{|c|c|c|c|c|}
\hline \multirow[t]{2}{*}{ Descrição dos canais } & \multirow[t]{2}{*}{ Comprimento de onda $(\mu \mathrm{m})$} & \multicolumn{2}{|c|}{$\begin{array}{c}\text { Coeficiente de calibração } \\
\left(\mathrm{Wm}^{-2} s r^{-1} \mu \mathrm{m}^{-1}\right)\end{array}$} & \multirow[t]{2}{*}{$\begin{array}{c}\text { Constante solar } \\
\left(\mathrm{Wm}^{-2} \mu \mathrm{m}^{-1}\right)\end{array}$} \\
\hline & & $\mathrm{a}$ & b & \\
\hline B 1 (azul) & $0,45-0,52$ & $-1,52$ & 193,0 & 1957,00 \\
\hline B 2 (verde) & $0,53-0,61$ & $-2,84$ & 365,0 & 1826,00 \\
\hline B 3 (vermelho) & $0,62-0,69$ & $-1,17$ & 264,0 & 1554,00 \\
\hline B 4 (infrav. próximo) & $0,78-0,90$ & $-1,51$ & 221,0 & 1036,00 \\
\hline B 5 (infrav. médio & $1,57-1,78$ & $-0,37$ & 30,2 & 215,00 \\
\hline B 6 (infrav. termal) & $10,4-12,5$ & 1,2378 & 15,303 & - \\
\hline B 7 (infrav. médio) & $2,10-2,35$ & $-0,15$ & 16,5 & 80,67 \\
\hline
\end{tabular}

Fonte: Serviço Geológico dos Estados Unidos da América

Do ponto de vista operacional, foram considerados os cossenos de cos (e) e o cos (i) para a correção do efeito topográfico, de forma que o $\cos (i)$ representa o ângulo entre a fonte de energia e a normal à superfície e foi obtido de acordo com a expressão (06) enquanto o cos (e) representa o ângulo entre a fonte e a inclinação do terreno e foi obtido através da expressão (07), implementadas através do operador matemático do ArcGis 9.3.1.

Cos_i $=\operatorname{Cos}\left(\left(\right.\right.$ Float $(\pi / 180) *$ Float $\left.\left(90 \_45.5278\right)\right)$ IF(SLOP"METERS" $\left.==0.0\right) \operatorname{OrCos}($ Float $(\pi / 180) *$ Float(90_45. $5278)) * \operatorname{Cos}($ Float $(\pi / 180) *$ Float(“SLOPMETERS"))+Sin(Float( $\pi / 180) *$ Float(90_45.5278))*Sin(Float( $\pi / 18$ 0)*Float(“SLOPMETERS"))*Cos(Float( $\pi / 180) *$ Float(48.1072)-Float(ASPECT))

Sendo que $\pi$ é uma constante, considerada aqui até sua trigésima primeira decimal, 45.5278 era a elevação do Sol no momento da passagem do sensor pela área de estudo, "SLOPMETERS" é a declividade do terreno obtida em graus, 48.1072 era o azimute solar no momento da passagem do sensor e ASPECT é o azimute do terreno.

Já o Cos (e) foi obtido pela expressão (12):

$$
\text { Cos_e }=\operatorname{Cos}(\text { Float }(\text { "SLOPMETERS") * Float }(\pi / 180))
$$


Por fim, as imagens foram normalizadas topograficamente, como explicita a Figura (02), a partir da expressão (08):

$$
N T P=I F\left(\cos \_i<=0.0\right) \operatorname{Or}\left(\left(\left[B a n d a \_C o r r\right]{ }^{*} \cos \_e\right) /\left(\cos \_i * \cos \_e\right)\right)
$$

Sendo IF e Or funções booleanas do operador.

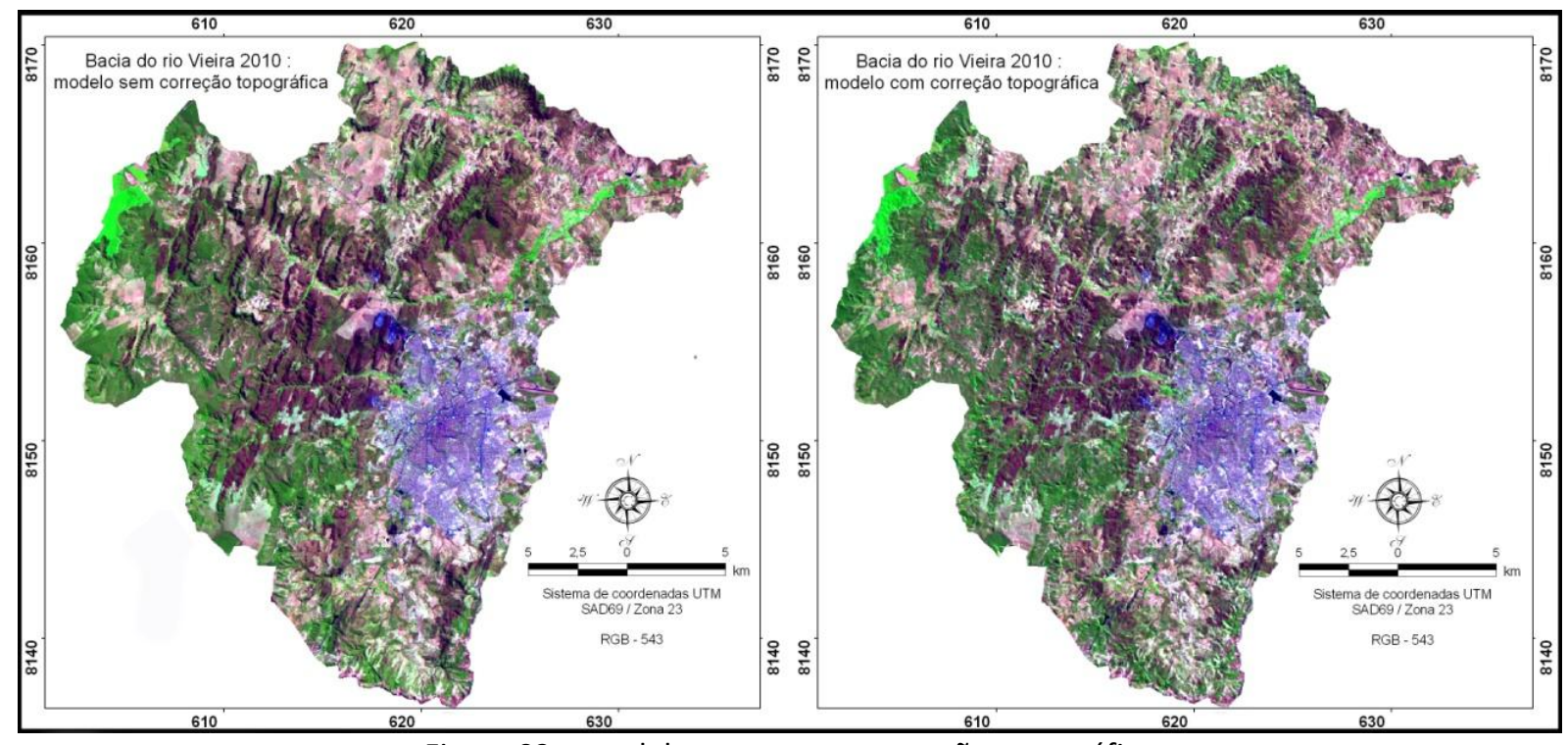

Figura 02 - modelos sem e com correção topográfica

No passo seguinte, posterior aos tratamentos supramencionados, foram montados os elementos para iniciar a classificação do Uso/Cobertura da Terra. Dentre estes elementos destaca-se o Índice de Vegetação por Diferença Normalizada - (NDVI) que é o resultado da razão entre a diferença da banda do infravermelho próximo (banda $4=\rho_{4}$ ) e a do vermelho (banda $3=\rho_{3}$ ), normalizado pela soma das mesmas, de forma que pode ser expressa pela equação (09).

$$
N D V I=\frac{\rho_{4}-\rho_{3}}{\rho_{4}+\rho_{3}}
$$

Os valores de (NDVI) variam de -1 a 1 e é um indicativo das condições de densidade, porte e saúde da vegetação. Os valores próximos de 0 indicam superfície com pouca vegetação; os valores próximos de 1 indicam superfícies vegetadas a densamente vegetadas. Já os valores menores que 0 indicam a presença de água, sombra, queimadas ou nuvens na cena. 
A transformação Tasseled Cap também foi um importante componente para a classificação. Nesta transformação seis bandas do sensor TM são sintetizadas em três novas componentes: (01) a componente brightness, que é a soma ponderada de todas as bandas e está relacionada à variação espectral dos solos; (02) a componente greenness está relacionada ao vigor da vegetação e é a diferença entre o canal do infravermelho próximo e os demais; (3) a componente wetness, que é o contraste entre o infravermelho médio e os demais canais (Gleriani et al., 2003). Cada componente foi obtida a partir das equações 10, 11 e 12.

$$
\begin{aligned}
& \mathrm{BR}=0,3037 * \operatorname{tm} 1+0,2793 * \operatorname{tm} 2+0,4743 * \operatorname{tm} 3+0,5585 * \operatorname{tm} 4+0,5082 * \operatorname{tm} 5+0,1863 * \operatorname{tm} 7 \\
& \mathrm{GR}=0,2848 * \operatorname{tm} 1,2435 * \operatorname{tm} 20,5436 * \operatorname{tm} 3+0,7243 * \operatorname{tm} 4+0,0840 * \operatorname{tm} 5-0,1800 * \operatorname{tm} 7
\end{aligned}
$$$$
\mathrm{WT}=0,1509 * \operatorname{tm} 1+0,1973 * \operatorname{tm} 2+0,3279 * \operatorname{tm} 3+0,3406 * \operatorname{tm} 4-0,7112 * \operatorname{tm} 5+0,4572 * \operatorname{tm} 7
$$

$\mathrm{Na}$ etapa seguinte foram definidas as classes de uso/cobertura da terra a serem mapeadas. A elaboração desta legenda obedeceu ao esquema teórico apresentado por Heymann (1994), conforme Figura 03.

No que diz respeito à classificação, o método foi o supervisionado e o algoritmo classificador foi o de árvore de decisão. Este é um tipo de classificador de múltiplos estágios que pode utilizar uma pilha de imagens independentes do sistema de projeção (ENVI, 2010). As regras de uma árvore de decisão permitem classificar as imagens utilizando dados temporais, além de derivadas de MNT ou de outras variáveis.

Assim, para os mapeamentos realizados para os anos de 1985, 1995 e 2010, foram utilizados tasseled cap de inverno, NDVI de inverno, as bandas 3, 4, 5 e 7 das imagens de inverno e o MNT, totalizando 10 componentes para a classificação. 


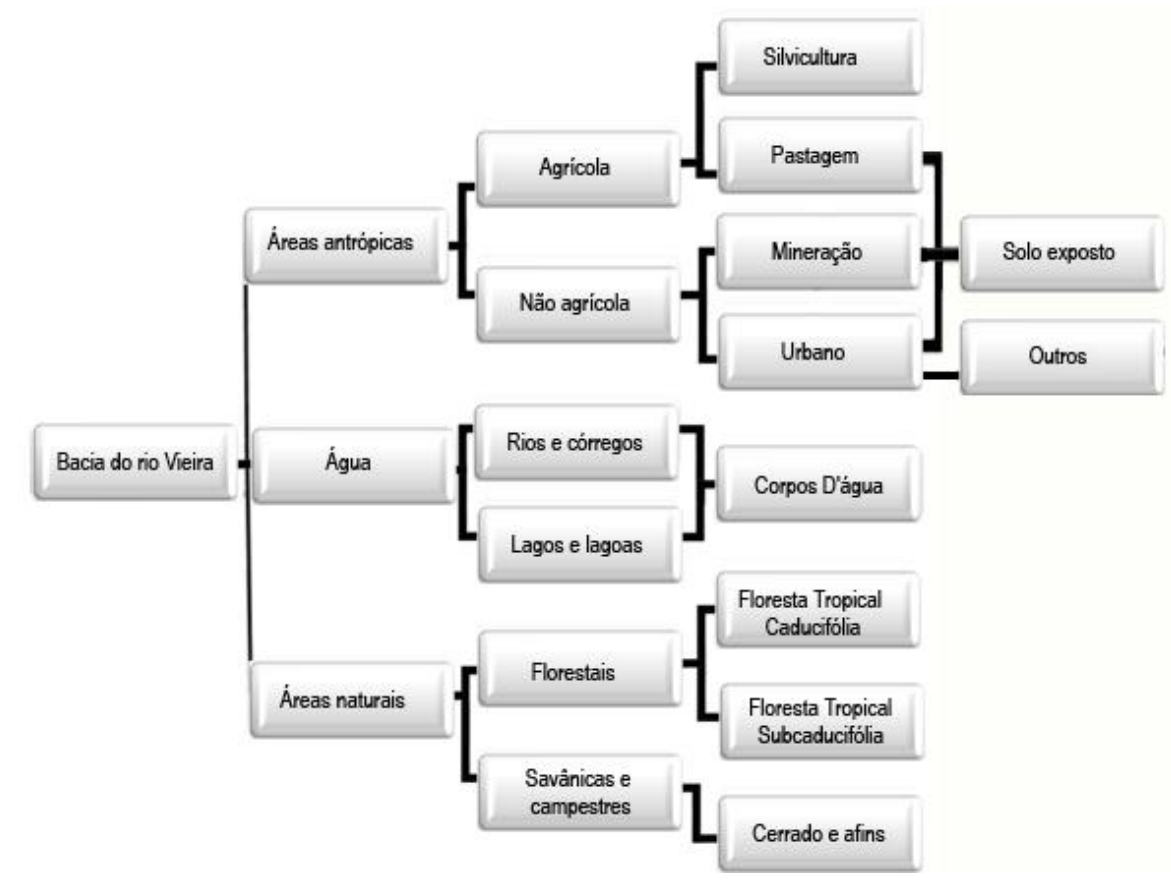

Figura 03 - hierarquização de legenda para mapeamento do uso/cobertura da terra.

Após a classificação de Uso/Cobertura da Terra, seguiram-se os procedimentos para a validação dos mapeamentos. Os instrumentos para a validação dos mapeamentos foram fornecidos pela matriz de confusão como a acurácia geral e índice Kappa.

A matriz foi elaborada com auxílio de produtos cartográficos externos e a partir da análise de amostras de conjuntos de pixels distribuídos pelos sistemas de uso/cobertura da terra de cada ano mapeado alem de fotointerpretação das imagens de 1985, 1995 com base nas imagens de 2010 e trabalhos de campo para validação das imagens de 2010. Para o ano de 1985, setenta e três pontos amostrais foram colhidos, para o ano de 1995, oitenta e quatro pontos de amostras foram testados, e para o ano de 2010, oitenta e dois pontos amostrais foram checados.

Cabe destacar que a classe do Urbano foi identificada de maneira separada, através do recorte das imagens dos três períodos, com base no perímetro urbano de cada ano. Dessa forma, foi possível obter a área edificada dentro da área urbana, e está foi denominada de urbano.

Posteriormente a elaboração da matriz utilizou-se a equação 13 para se obter o coeficiente Kappa, tendo em vista que ele pode revelar uma melhor estimativa sobre a acurácia de um determinado mapeamento, tendo em vista que nos cálculos deste coeficiente são considerados todos os componentes da matriz. 


$$
K=\frac{x \sum_{i=1}^{r} x_{i i}-\sum_{i=1}^{r} x_{i+} x_{+i}}{x^{2}-\sum_{i=1}^{r} x_{i+} x_{+i}}
$$

Sendo que $X$ são elementos da matriz de confusão; $r$, o número de categorias presentes na matriz; Xii são os elementos da diagonal principal; Xi+ é total da linha para uma dada categoria informacional; e X+i é total da coluna para a categoria.

\section{RESULTADOS E DISCUSSÕES}

Do ponto de vista dos resultados dos mapeamentos o coeficiente Kappa, conforme as tabelas 04, 05 e 06, indicaram níveis de excelência para todos os anos mapeados.

No que concernente a analise dos resultados, a Bacia do Rio Vieira apresentou dois domínios bem marcados: um, de ocupação natural o qual compreende as classes da vegetação natural e água presentes nas Figuras 4, 5 e 6, e o segundo, marcado pelas áreas antrópicas de ocupação intensa.

\begin{tabular}{|c|c|c|c|c|c|c|c|c|c|c|}
\hline Classes & Cerrado & $\mathrm{FTC}^{5}$ & $\mathrm{FTS}^{6}$ & Pastagem & Mineração & Urbano & $\begin{array}{c}\text { Solo } \\
\text { exposto }\end{array}$ & Água & Outros & Total \\
\hline Cerrado & 38 & & 2 & & & & & & & 40 \\
\hline FTC & & 37 & & 3 & & 4 & & & & 44 \\
\hline FTS & 3 & & 22 & & & & & & & 25 \\
\hline Pastagem & & 1 & & 153 & & & 7 & & 4 & 165 \\
\hline Mineração & & & & & 16 & 6 & & 3 & & 25 \\
\hline Urbano & & 3 & & 2 & 2 & 161 & & & 2 & 170 \\
\hline $\begin{array}{c}\text { Solo } \\
\text { exposto }\end{array}$ & & & & & & & 89 & & 1 & 90 \\
\hline Água & & & & & 3 & & & 12 & & 15 \\
\hline Outros & 5 & 2 & & 15 & 2 & & 2 & & 14 & 40 \\
\hline Total & 46 & 43 & 24 & 173 & 23 & 171 & 98 & 15 & 21 & 614 \\
\hline
\end{tabular}

Tabela 04 - Matriz de confusão do mapeamento do ano de 1985.

${ }^{5}$ Floresta Tropical Caducifólia.

${ }^{6}$ Floresta Tropical Subcaducifólia 
Tabela 05 - Matriz de confusão do mapeamento do ano de 1995.

\begin{tabular}{|c|c|c|c|c|c|c|c|c|c|c|c|}
\hline Classes & Cerrado & FTC & FTS & $\begin{array}{c}\text { Pastage } \\
\mathrm{m}\end{array}$ & Eucalipto & Mineração & Urbano & $\begin{array}{l}\text { Solo } \\
\text { exposto }\end{array}$ & Água & Outros & Total \\
\hline Cerrado & 39 & & 1 & & 1 & & & & & & 41 \\
\hline FTC & & 40 & & 2 & & & 18 & & & & 60 \\
\hline FTS & 3 & & 20 & & 13 & & & & & & 36 \\
\hline Pastagem & & & & 155 & & & & 12 & & 6 & 173 \\
\hline Eucalipto & & & 3 & & 142 & & & & & & 145 \\
\hline Mineração & & & & & & 18 & 3 & & 5 & & 26 \\
\hline Urbano & & 1 & & 1 & & 2 & 155 & & 1 & & 160 \\
\hline $\begin{array}{c}\text { Solo } \\
\text { exposto }\end{array}$ & & & & & & & & 80 & & 4 & 84 \\
\hline Água & & & & & & 3 & & & 14 & & 17 \\
\hline Outros & 4 & 3 & & 17 & & & & 4 & & 20 & 48 \\
\hline Total & 46 & 44 & 24 & 175 & 156 & 23 & 176 & 96 & 20 & 30 & 790 \\
\hline
\end{tabular}

Tabela 06 - Matriz de confusão do mapeamento do ano de 2010.

\begin{tabular}{|c|c|c|c|c|c|c|c|c|c|c|c|}
\hline Classes & Cerrado & FTC & FTS & Pastagem & Eucalipto & Mineração & Urbano & $\begin{array}{c}\text { Solo } \\
\text { exposto }\end{array}$ & Água & Outros & Total \\
\hline Cerrado & 40 & & 2 & & & & & & & & 42 \\
\hline FTC & & 45 & & 2 & & & 4 & & & & 51 \\
\hline FTS & 2 & & 22 & & 16 & & & & & 1 & 41 \\
\hline Pastagem & & & & 153 & & & & 3 & & 3 & 159 \\
\hline Eucalipto & & & 2 & & 140 & & & & & & 142 \\
\hline Mineração & & & & & & 15 & 4 & & 4 & & 23 \\
\hline Urbano & & 2 & & & & 2 & 159 & & 2 & 2 & 167 \\
\hline $\begin{array}{l}\text { Solo } \\
\text { exposto }\end{array}$ & & & & & & & & 89 & & 1 & 90 \\
\hline Água & & & & & & 4 & & & 12 & & 16 \\
\hline Outros & 7 & 1 & & 18 & & & & 7 & & 21 & 54 \\
\hline Total & 49 & 48 & 26 & 173 & 156 & 21 & 167 & 99 & 18 & 28 & 785 \\
\hline
\end{tabular}

É importante ressaltar que a determinação das áreas em naturais e antrópicas, por sua vez, não marcam a ausência de atividades antrópicas nas ditas áreas naturais bem como ausência de vegetação nativa nas áreas antrópicas. Tal fato fica claro nas áreas de vegetação natural que são cortadas por estradas, nas quais se verificou, ao longo das mesmas, vários pontos de erosão superficial adentrando para as áreas do sub-bosque, além de atividades ligadas ao extrativismo vegetal, principalmente em função da coleta de pequi, onde as pessoas desbastam a vegetação herbácea - arbustiva abrindo trilhas ao longo das áreas vegetadas.

De forma semelhante, a presença de vegetação natural ocorre nas áreas de uso antrópico, sobretudo, dentro do perímetro urbano. Como exemplo, pode-se citar as áreas de parques, alamedas e as áreas de expansão urbana que, embora estejam dentro dos limites urbanos, 
ainda não possuem edificações, permitindo o desenvolvimento inicial da vegetação, especialmente entre os anos de 1985 e 1995. Desta forma, as mudanças abruptas de uso/cobertura da terra dentro de cada domínio podem contribuir para a oscilação da temperatura e do albedo de superfície, principalmente considerando o efeito de borda das áreas desmatas e o maior consumo de energia térmica da vegetação dentro do espaço urbano.

Para o ano de 1985, os domínios naturais representam a somatória das áreas de Cerrado e formações afins, as áreas de Floresta Tropical Caducifólia e Subcaducifólia e as áreas de lagoas presentes na bacia e exposto na Figura 4. As áreas de uso antrópico correspondiam à ocorrência de mineração, solo exposto, urbano, pastagens mais a classe outros.

Em termos numéricos, o ano de 1985 apresentou 46,34\% (267,99 km²) de áreas correspondentes aos domínios naturais na bacia do Rio Vieira e 53,66 \% (310,32 km²) de áreas antrópicas de uso intenso, conforme pode ser verificado pela somatória das classes detalhadas na Tabela 07.

De acordo com a Figura 5 de uso/cobertura da terra em 1995, a bacia do Rio Vieira já apresentava áreas destinadas à silvicultura. Certamente, esse acontecimento está atrelado ao fato de que, ao final da década de 1980, o eucalipto que era plantado nas áreas noroeste e norte da mesorregião do Norte de Minas, perderam espaço por força da criação de unidades de conservação próximo à região do projeto Jaíba. Como, exemplo pode ser citados os decretos federais no 94.608 de 14/07/1987 e de no 98.182 de 26/09/1989, os quais criaram a reserva indígena do Xacriabá entre os Municípios de Itacarambí e São João das Missões, e a área de preservação permanente Cavernas do Peruaçu, respectivamente. Além da área noroeste do Norte de Minas se tornar produtora de grãos e sementes. 


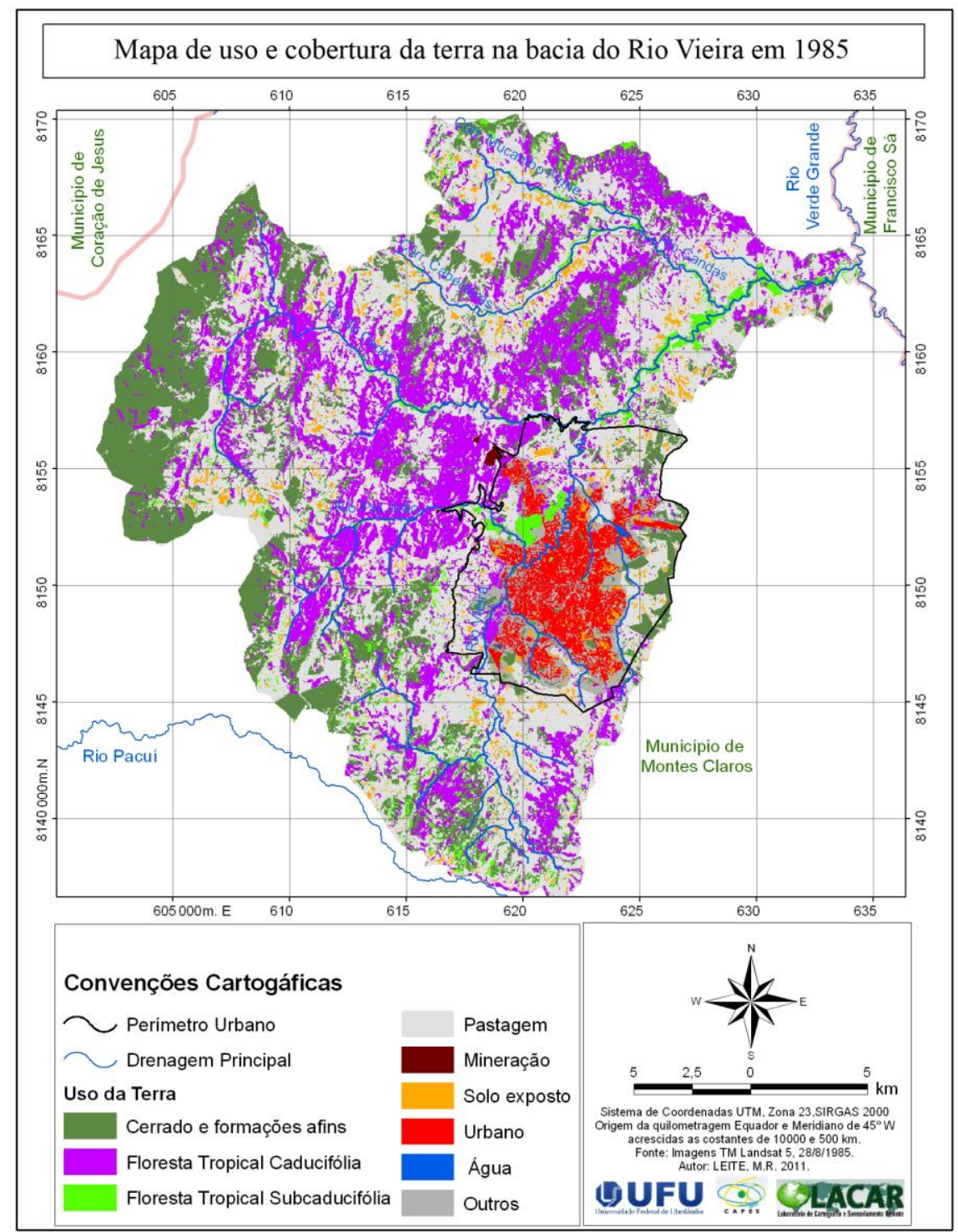

Figura 4 - Mapa de Uso/Cobertura da terra na bacia do Rio Vieira em 1985.

Tabela 07 - Uso/Cobertura da terra na bacia do Rio Vieira em 1985

\begin{tabular}{ccc}
\hline Uso/Cobertura da terra & \multicolumn{2}{c}{ Área } \\
\cline { 2 - 3 } & $\mathbf{k m}^{\mathbf{2}}$ & $\mathbf{( \% )}$ \\
\hline Cerrado e formações afins & 119,50 & $\mathbf{2 0 , 6 6}$ \\
Floresta Tropical Caducifólia & 129,80 & 22,44 \\
Floresta Tropical Subcaducifólia & 18,40 & 3,18 \\
Pastagem & 252,62 & 43,69 \\
Mineração & 0,61 & 0,11 \\
Solo exposto & 16,85 & 2,91 \\
Urbano & $\mathbf{2 2 , 7 4}$ & 3,93 \\
Água & 0,29 & 0,05 \\
Outros & 17,50 & 3,02 \\
\hline Total & $\mathbf{5 7 8 , 3 1}$ & $\mathbf{1 0 0 , 0 0}$ \\
\hline
\end{tabular}




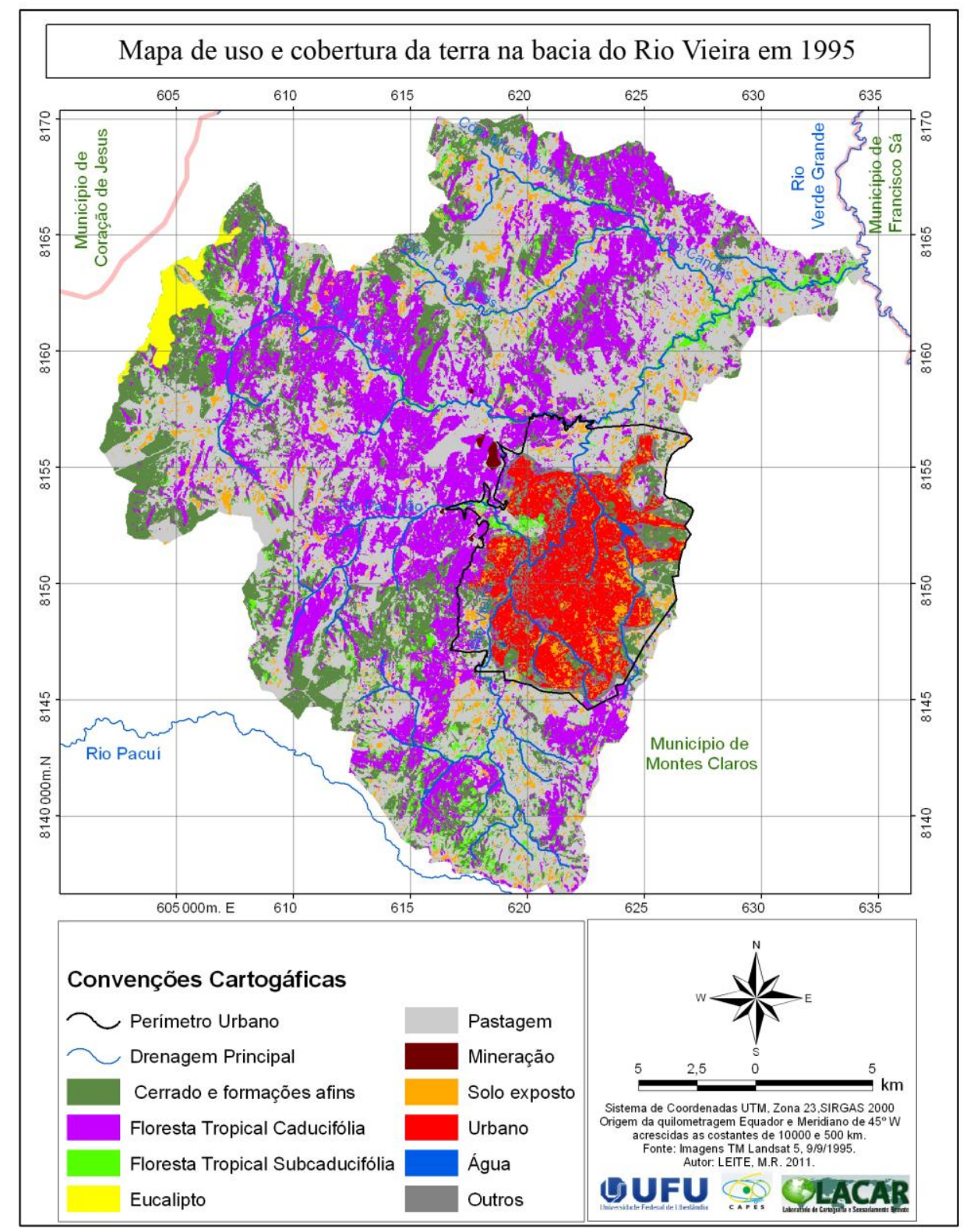

Figura 5 - Mapa de Uso/Cobertura da terra na bacia do Rio Vieira em 1995.

Esse processo, somado às ações de proteção à Mata seca (Floresta Tropical Caducifólia), fez com que o eucalipto começasse a ser plantado basicamente nas áreas centrais e leste do Norte do Estado de Minas. Fato que exerceu, por sua vez, grande pressão sobre as áreas de Cerrado, sobretudo na região da Serra do Espinhaço e sobre os planaltos residuais da área central do Norte de Minas, refletindo no uso/cobertura da terra da bacia em estudo. A relação de ocorrência dos domínios naturais e antrópicos da bacia do Rio Vieira, do ano de 1985 para 1995 , assinalou um aumento de $2,78 \mathrm{~km}^{2}$ de áreas naturais, representando 0,48\% 
do total, já que as somas das classes da Tabela 08 apontam para 46,82\% $\left(270,77 \mathrm{~km}^{2}\right)$ de áreas com vegetação natural contra 53,18\% (307,54km²) de uso antrópico da terra em 1995. As classes individuais de uso/cobertura da terra, entretanto, apresentaram oscilações mais marcantes dentro deste período. É o caso das áreas de cerrado que registraram perdas da ordem de $18,87 \mathrm{~km}^{2}$ de área, evidenciando uma supressão de mais e $15 \%$ de seu total em 1985. Dentre as classes de uso/cobertura que mais pressionaram o Cerrado destaca-se 5,98 $\mathrm{km}^{2}$ de eucalipto, as áreas de pastagem e, em menor intensidade, as áreas urbanas.

Desta forma, o aumento em área superficial das atividades mineradoras entre o ano 1985 e 1995 representa novas unidades cujas atividades estavam ligadas a extração de pedra, brita e o chamado pó de pedra, muito utilizado na construção civil e que, na cidade de Montes Claros, foi utilizado para o calçamento das vias públicas durante a década de 1990.

Tabela 08 - Uso/Cobertura da terra na bacia do Rio Vieira em 1995.

\begin{tabular}{ccc}
\hline Uso/Cobertura da terra & \multicolumn{2}{c}{ Área } \\
\cline { 2 - 3 } & $\mathbf{k m}^{\mathbf{2}}$ & $\mathbf{( \% )}$ \\
\hline Cerrado e formações afins & 100,63 & 17,40 \\
Floresta Tropical Caducifólia & 150,46 & 26,02 \\
Floresta Tropical Subcaducifólia & 19,08 & 3,30 \\
Eucalipto & 5,89 & 1,02 \\
Pastagem & $\mathbf{3 9 , 0 2}$ \\
Mineração & 0,13 \\
Solo exposto & 225,63 & 0,15 \\
Urbano & $\mathbf{2 4 , 0 5}$ & 6,69 \\
Água & 38,71 & 0,10 \\
Outros & 0,6 & $\mathbf{2 , 1 6}$ \\
\hline Total & 12,51 & $\mathbf{1 0 0 , 0 0}$ \\
\hline
\end{tabular}

O aumento de áreas, cujo solo estava desprotegido ou com vegetação altamente rarefeita, passou de 16,85 km² em 1985 para 24,05 km² em 1995, configurando um aumento de mais de $42 \%$ de área em relação aos dados de 1985 . Esses dados são justificados por dois processos bem destacados nos mapeamentos, um de efeito local, como o caso da expansão da área urbana, e o outro mais generalizado que está ligado ao avanço das áreas de pastagem sobre as áreas de cerrado.

No primeiro caso, a expansão urbana da cidade de Montes Claros teve influência direta da grande atração populacional, iniciada a partir da década de 1970, com a instalação de 
indústrias no perímetro urbano, atraídas pelos incentivos fiscais da Superintendência do Desenvolvimento do Nordeste - SUDENE. Leite (2003) argumenta que a década de 1970 é o marco transitório entre a Montes Claros rural e a urbano-industrial. O resultado desta atração populacional foi o rápido e, em muitos casos, desordenado crescimento da malha urbana da cidade. Leite e Pereira (2008), avaliando os dados censitários do IBGE entre as décadas de 1960 e 2000, argumentam que a população urbana de Montes Claros saltou de 155.483 em 1980, para 289.183 habitantes em 2000, provocando um aumento de mais de 85\% da população em 20 anos.

Para atender a essa nova população, a cidade de Montes Claros assumiu um crescimento médio, entre os anos de 1985 e 1995, de 1,6 km²/ano, que resultou em um crescimento total da área edificada neste período de $15,97 \mathrm{~km}^{2}$. O fato é que a demanda por locais de construção dentro do espaço urbano implicaram em desmatamento das áreas vegetadas dentro deste espaço, deixando como resultado grande quantidade de áreas expostas.

As demais áreas de solo exposto presentes na bacia, de forma mais geral, estão ligadas ao avanço das áreas de pastagem sobre o cerrado. Tendo em vista que as áreas de Floresta Tropical Caducifólia e Subcaducifólia registraram aumento de 20,66 km² e 0,68 km², respectivamente, entre os anos de 1985 e 1995. Possivelmente, esse aumento em área, das florestas, deve-se ao Decreto Federal 750, que incluiu essas formações no bioma Mata Atlântica em 1993. Além disso, em 1987, foi criado o Parque Municipal da Sapucaia, com $0,38 \mathrm{~km}^{2}$ de área de Floresta Caducifólia dentro da bacia, que já vinha sendo foco de preocupação de ambientalistas, principalmente contra as práticas de queimadas que destruía a vegetação seca durante o período de inverno.

Este fato mobilizou a sociedade em torno da causa das Florestas Tropicais Caducifólias e Subcaducifólia da presente bacia na qual a cobrança por fiscalização e as crescentes denúncias surtiram efeito em prol da conservação destas formações, inclusive com a idéia de criação de uma unidade de conservação que visasse proteger e conservar o complexo de grutas e abrigos da Lapa Grande, dentro da bacia, cuja vegetação predominante é de Florestas.

Como consequência desse processo, as áreas de cerrado se tornaram fronteiras de avanço para pastagem e eucalipto na bacia do Rio Vieira. Como resultado, muitas áreas apresentaram processo de erosão superficial acelerado, onde antes era área vegetada, áreas 
de pastagem e cultivo abandonados, em função da redução do trabalho nas áreas rurais, apresentaram níveis de degradação da vegetação, os quais culminaram na exposição direta dos solos, aumentando em cerca de $7 \mathrm{~km}^{2}$ em relação ao ano de 1985.Os índices de desmatamento das áreas de Cerrado e o avanço das áreas de solo em exposição, contudo, tenderiam a diminuir em relação aos valores do ano de 2010. Com efeito, o ano de 2010 apresentou a maior quantidade de áreas naturais entre os anos mapeados, tanto no que pertencem as áreas de floresta quanto às áreas de Cerrado.

Ao todo, foram verificados 55,81\% $\left(322,78 \mathrm{~km}^{2}\right)$ de áreas naturais e $44,19 \%\left(255,53 \mathrm{~km}^{2}\right)$ de áreas antrópicas, representando um aumento da ordem de 8,99\% de áreas vegetadas em relação ao ano de 1995, e de aproximadamente 10\% em relação ao ano de 1985.

Do ponto de vista quantitativo, as áreas de Cerrado foram as que mais se recuperaram, obviamente porque foi a classe de uso/cobertura mais afetada durante os anos anteriores. Um dos motivos da regeneração, não só das áreas de Cerrado, mas também das áreas vegetadas da bacia, foi à criação do Parque Estadual da Lapa Grande pelo Decreto Estadual no 44.204 , de 10 de janeiro de 2004. Trata-se de um complexo de proteção integral de aproximadamente $96,64 \mathrm{~km}^{2}$ de área, dos quais $85,55 \%$ de seus limites encontram-se dentro da bacia do Rio Vieira, como aponta a Figura 5.

Com efeito, foram recuperadas 48,39 $\mathrm{km}^{2}$ de áreas de Cerrado, entre os anos 1995 e 2010, isto é, mais de $48 \%$ de áreas recuperadas em 15 anos. Realidade que evidencia uma média anual de recuperação de $3,23 \mathrm{~km}^{2} /$ ano.

No que diz respeito às áreas das Florestas Tropicais Caducifólia e Sucaducifólia, desde 1987 essas áreas vinham sendo preservadas por força de criação de parques municipais e pelas crescentes disputas judiciais entre produtores e ambientalistas. fato que culminou no Decreto no 6.660/08 ${ }^{7}$, que regulamenta a Lei Federal no 11.428, de 2006, a qual inseriu, definitivamente, as Florestas Caducifólias e Subcaducifólias na lei de preservação do bioma Mata Atlântica impedindo sua derruba. Neste contexto, as florestas apresentaram crescimento, em área superficial, de 3,62 km², sendo 1,67 de Floresta tropical Caducifólia e $1,95 \mathrm{~km}^{2}$ de Sucaducifólia, como destaca a Tabela 09.

\footnotetext{
${ }^{7}$ A Assembléia Legislativa de Minas Gerais promulgou a lei que retira a mata seca, na região Norte do Estado, da área de preservação ambiental da Mata Atlântica. Através da Lei 19.096/2010, publicada dia 04 de agosto de 2010 no Diário Oficial do Estado.
} 


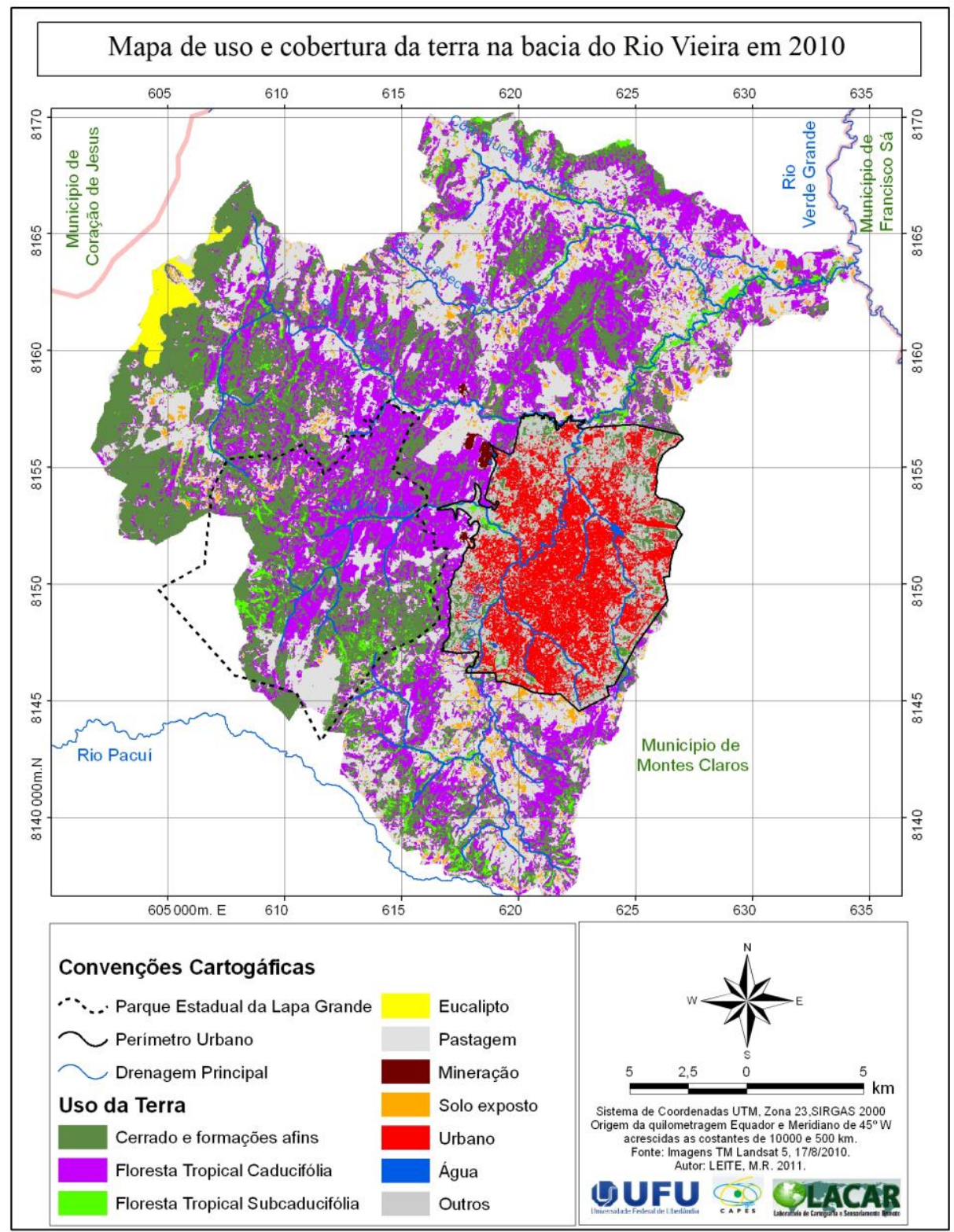

Figuras 6 - Mapa de Uso/Cobertura da terra da bacia do Rio Vieira em 2010.

Tabela 09 - Uso/Cobertura da terra na bacia do Rio Vieira em 2010.

\begin{tabular}{ccc}
\hline Uso/Cobertura da terra & \multicolumn{2}{c}{ Área } \\
\cline { 2 - 3 } Cerrado e formações afins & $\mathbf{k m} \mathbf{2}$ \\
Floresta Tropical Caducifólia & 149,02 & 25,77 \\
Floresta Tropical Subcaducifólia & 152,13 & 26,31 \\
Eucalipto & 21,03 & 3,64 \\
Pastagem & 5,14 & 0,89 \\
Mineração & 159,53 & 27,59 \\
Solo exposto & 1,12 & 0,19 \\
Urbano & 11,82 & 2,04 \\
Água & 47,52 & 8,22 \\
Outros & 0,60 & 0,10 \\
Total & 30,40 & 5,25 \\
\hline
\end{tabular}


As áreas de eucalipto apresentaram baixa de 0,75 km² em relação aos dados de 1995 . Quanto às áreas de mineração apresentaram aumentos progressivos em relação aos anos mapeados atingindo um total de $0,51 \mathrm{~km}^{2}$. Tal aumento muito se deu em função da expansão urbana e, sobretudo, da exploração de calcário para a exportação de cimento para outros centros urbanos do Brasil. A Figura 07 traduz visualmente as relações de avanço e regressão das classes de uso/cobertura entre os anos mapeados, de forma que as classes de uso/cobertura da terra refletem o processo histórico ocupacional da bacia.

O ano 1985, por exemplo, apresenta uma diferença entre as classes de uso antrópico em relação aos ambientes naturais de $42,33 \mathrm{~km}^{2}$, tal fato marca uma tendência de uso antrópico da bacia, tendo em vista a proximidade temporal com as décadas de 1970 e 1960, que são datas nas quais o movimento populacional no sentido campo - cidade estava em processo.

A classe de pastagem pode ser citada como indicador de uso antrópico da bacia. Desta maneira, somente em 1985 a classe em análise representava 46,71\% da bacia, isto é, mais que o dobro das classes de Cerrado e florestas, fato que salienta uma intensa atividade antrópica nas áreas rurais.

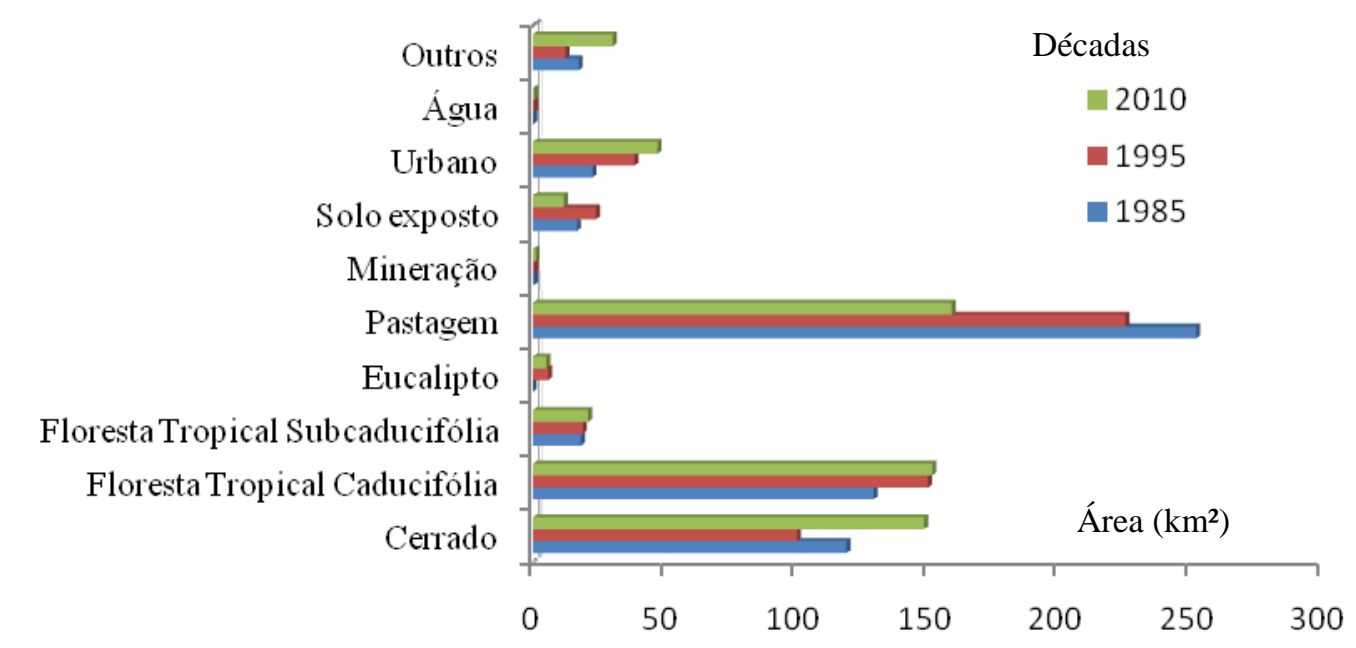

Figura 07 - Gráfico de relação de uso/cobertura da terra entre os anos mapeados.

Para o ano de 1995, registra-se uma redução, em área, de 26,99 km² das áreas de pastagem. Essa redução se dá principalmente em função do avanço das classes de uso urbano e de solo exposto, as quais somadas chegam a $23,17 \mathrm{~km}^{2}$ de área, que representa $85,85 \%$ da redução da classe pastagem. O aumento considerável das áreas urbanas em 1995 está atrelado à consolidação do Município de Montes Claros como urbano - industrial, na qual a população 
urbana do Município na década de 1990 já era de mais de 200.000 mil habitantes, conforme destaca Leite e Pereira (2008).

As perdas de espaço para a produção rural, diante da recuperação das florestas, além da chegada do eucalipto, por conta de pressões externas, implicaram numa redução de áreas de Cerrado, entre 1985 e 1995, que equivaleriam a aproximadamente 3.774 campos de futebol. O resultado disto não foi somente o aumento de áreas para o pasto e para a produção de carvão, mas também o aumento das áreas de solo em exposição.

Tal realidade pode ser verificada ao se comparar os mapas de uso/cobertura da terra do ano de 1985 e 1995, com enfoque nas áreas W da bacia, onde se verifica ausência da classe citada no primeiro mapa e a presença da classe em vários pontos no segundo mapa. Neste contexto, o ano de 1995 também apresenta maior concentração de áreas antrópicas em relação às naturais, sendo que a diferença entre esses domínios é da ordem de $36,77 \mathrm{~km}^{2}$ de área.

Em 2010, entretanto, esta realidade se inverte, isto é, as áreas naturais superaram as áreas antrópicas em 52,01 km², revelando uma tendência de recuperação das áreas de vegetação natural. A recuperação das áreas vegetadas, por sua vez, influiu na redução de outras classes de uso/cobertura, como a redução dos valores de solos em exposição da ordem de $50,85 \%$ em relação ao ano de 1995, destacando aumento em todas as classes de vegetação natural em relação às classes de uso antrópico.

A classe de uso/cobertura da terra denominada de outros não apresenta, entretanto, esta dinâmica, tendo em vista que seus valores apresentam diminuição para o ano de 1995 e aumento considerável para o ano de 2010. Esse fato está atrelado ao crescimento urbano, já que em 1985 as áreas de expansão urbana eram separadas por espaços urbanos vazios, fato que elevou os valores dessa classe em 1985. Em 1995, esses espaços foram preenchidos pelas áreas edificadas, fato que promoveu a diminuição dos valores desta classe, já para o ano de 2010 uma nova expansão da área urbana implicou em novos espaços vazios dentro do perímetro urbano, culminando na elevação dos valores, em área, desta classe.

O avanço das áreas vegetadas sobre as demais classes de uso/cobertura da terra na bacia do Rio Vieira, no ano de 2010, está relacionada aos conflitos entre ambientalistas e produtores rurais que progressivamente tenderam para a criação de unidades de conservação sob tutela da lei, isto é, a inserção das Florestas Caducifólia e Subcaducifólia no bioma Mata Atlântica, 
mais as áreas de preservação permanente criadas dentro da bacia, decisivamente contribuíram para o reflorestamento nativo desta área.

O efeito espacial da recuperação de áreas vegetadas na bacia assinala uma tendência inversa entre os domínios de uso/cobertura da terra, conforme se avalia pelas curvas da Figura 08. Considerado o intervalo de tempo entre 1985 e 1995, o avanço percentual médio das áreas vegetadas sobre as áreas de uso antrópico foi de apenas $0,048 \%$ por ano, valor que corresponde a aproximadamente 0,278 km²/ano. Em relação aos anos de 1995 e 2010, o aumento das áreas naturais em relação às áreas antrópicas foi consideravelmente maior, já que os números revelam 8,99\% de avanço dos domínios naturais sobre os antrópicos, correspondendo a uma progressão de $0,60 \%$ ou $3,47 \mathrm{~km}^{2} / \mathrm{ano}$.

Sobre a perspectiva dos sistemas de uso/cobertura da terra a Tabela 10, traz os saldos percentuais das áreas de cada sistema de uso/cobertura da terra na bacia de estudo em relação aos anos mapeados e o balanço final de recuperação e perdas das áreas mapeadas. Destaque deve ser dado para as áreas de Cerrado, Floresta Tropical Caducifólia, urbano, solo exposto e pastagem entre os anos de 1985 a 1995 e as áreas de pastagem. Novamente, as classes de Cerrado e pastagem representam os valores extremos nos anos de 1995 e 2010, com destaque para as áreas de solo exposto, às quais apresentaram perdas consideráveis para o ano de 2010.

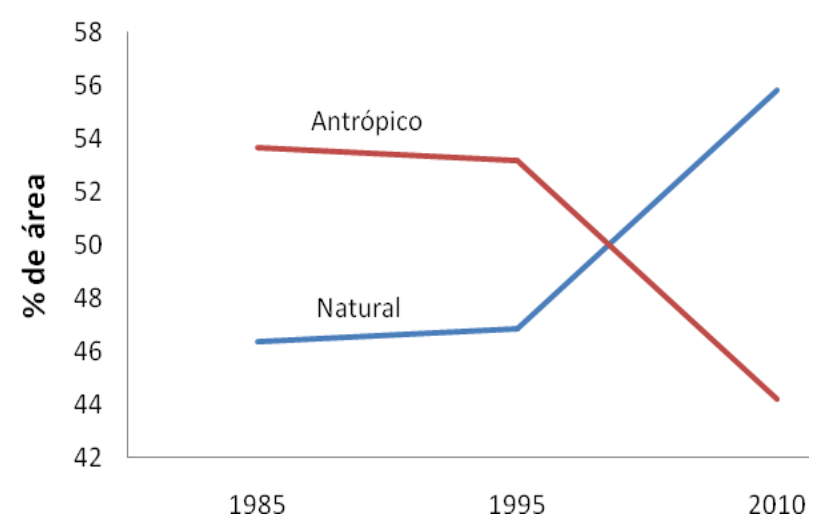

Figura 08 - Curvas de tendência entre os domínios de uso/cobertura da terra por ano mapeado.

A oscilação percentual dos sistemas de uso/cobertura da terra expostos na Tabela 10 evidencia, na realidade, o avanço e a regressão de determinada cobertura superficial em relação à outra, ou seja, os avanços das áreas de cerrado sobre outras classes significam maior cobertura vegetal sobre a superfície e todas as implicações que a presença de 
vegetação impõem sobre a superfície, maior presença de água, redução da incidência da radiação solar sobre os solos, entre outras.

Tabela 10 - Saldo de área em percentual por classe de uso/cobertura da terra entre os anos mapeados e balanço final de áreas mapeadas.

\begin{tabular}{|c|c|c|c|}
\hline Uso/Cobertura da terra & $\begin{array}{c}1985 \text { - } 1995 \\
(\%) \\
\end{array}$ & $\begin{array}{c}1995-2010 \\
(\%) \\
\end{array}$ & $\begin{array}{c}\text { Saldo final de } \\
1985 \text { - } 2010 \\
(\%)\end{array}$ \\
\hline Cerrado & $-15,79$ & 48,09 & 32,30 \\
\hline FTC & 15,92 & 1,11 & 17,03 \\
\hline FTS & 3,70 & 10,22 & 13,92 \\
\hline Eucalipto & 100,00 & $-12,73$ & 87,27 \\
\hline Pastagem & $-10,68$ & $-29,30$ & $-39,98$ \\
\hline Mineração & 22,95 & 49,33 & 72,28 \\
\hline Solo exposto & 42,73 & $-50,85$ & $-8,12$ \\
\hline Urbano & 70,23 & 22,76 & 92,99 \\
\hline Água & 106,90 & 0,00 & 106,90 \\
\hline Outros & $-28,51$ & 143,01 & 114,49 \\
\hline
\end{tabular}

Da mesma maneira, o avanço de sistemas de uso/cobertura da terra como solo exposto implica, também, em novas interações entre a superfície e a radiação incidente. Como, por exemplo, maior e mais rápido aquecimento da superfície (solo), ressecamento dos solos, maior fluxo de calor entre os horizontes dos solos, entre outros.

\section{CONSIDERAÇÕES FINAIS}

As possibilidades de mapeamentos foram, indubitavelmente, fomentadas pelos produtos e técnicas de sensoriamento remoto orbital. Corroborando essa argumentação, considera-se a área da bacia do Rio Vieira cujo valor é da ordem de $578,31 \mathrm{~km}^{2}$, uma área relativamente grande, considerando técnicas convencionais de mapeamento, e uma área relativamente pequena, considerando o aparato tecnológico disponibilizado pelos dispositivos imagiadores do planeta.

A posição geográfica, da bacia em questão, enfatiza ainda mais a importância do sensoriamento remoto nos modelos de monitoramento e gestão dos ambientes naturais e antrópicos, haja vista a possibilidade de discriminação de diferentes formações vegetais numa área caracterizada pela complexidade de diferenciação de tipos florestais. Principalmente, considerando o fato de que os indicadores de eficiência do mapeamento da 
cobertura vegetal natural, do presente trabalho, apontaram valores da ordem de 0.86 e 0.84 de confiabilidade, destacando uma relação de custo benefício altamente favorável ao sensoriamento remoto orbital.

Do ponto de vista operacional, o tempo de execução da metodologia descrita, desde a aquisição dos produtos orbitais até a validação dos mapeamentos, foi relativamente curto. Fato que merece destaque, sobretudo, porque permitiu a elaboração de uma vasta gama de informações temporais da bacia do Rio Vieira. Como exemplo, pode-se citar a inversão dos tipos de uso/cobertura apresentado na Figura 08 cujos valores revelam uma recuperação de $54,79 \mathrm{~km}^{2}$ de vegetação natural em 25 anos.

Com efeito, a diferença entre os domínios naturais e antrópicos da bacia em 1985 era de 43,33 $\mathrm{km}^{2}$ a mais de áreas antrópicas. Já para o ano de 2010 , essa diferença era de 67,25 $\mathrm{km}^{2}$ a mais de áreas naturais. Destaque deve ser dado para as áreas de Cerrado, como destacado na Tabela 10, em que 32,30\% foram recuperados, em relação ao ano de 1985. Para as áreas de florestas, ocorreu um aumento percentual de $30,95 \%$ de área em relação ao ano de 1985.

Como resultado da recuperação das áreas vegetadas, ocorreu uma redução da ordem de $39,98 \%$ da área de pastagem e de $8,12 \%$ de solo exposto em relação aos dados de 1985 . A redução da área de pastagem destaca, de forma implícita, a saída da população das áreas rurais, tanto das áreas da bacia como de outras áreas da região do Norte de Minas, propiciada pela grande atração populacional, ocorrida por volta da década de 1970, para a cidade de Montes Claros.

Resultado esse que afetou o espaço físico urbano deste município, culminando num aumento percentual da ordem de $92,99 \%$ da área edificada em relação ao ano de 1985 . É possível observar ainda que essa área tende a expandir ainda mais, haja vista que a classe de uso/cobertura denominada de outros apresentou uma redução da ordem de $28,51 \%$ para o ano de 1995, basicamente em função da expansão da área urbana edificada. Já para o ano de 2010, essa classe de uso/cobertura da terra apresentou um aumento da ordem de 143,01\%, revelando espaços prontos para receber edificações urbanas e dar sequência ao movimento expansionista da cidade. 


\section{REFERÊNCIAS BIBLIOGRÁFICAS}

ENVI 4.7., Decision Tree Classification:Tutorial, 2010. p.7

FAO. Food and Agriculture Organization of the United Nations. Planning for sustainable use of land resources. FAO land and water bulletin 2. Rome: FAO,1995. 67p.

GLERIANI, J. M., ANTUNES. M. A. H., EPIPHANIO J. C. N. Coeficientes da transformação espectral tasseled cap para uma cena com predomínio de latossolo roxo In:: Simpósio Brasileiro de Sensoriamento Remoto (SBSR) 05-10 abril 2003, Belo Horizonte. Anais, INPE,p. 101-107.

HEYMANN, Y. Corine land cover technical guide. Colaboração de Chris Steenmans, Guy Croisille e Michel Bossard. Luxembourg: European Commission, 1994. 136 p

IBGE, Instituto Brasileiro de Geografia e Estatística. Censo 2010, disponível em: http/www.ibge.gov.br, acessado em: 21/02/2011.

IBGE. Manual técnico de uso da terra. Manuais técnicos em geociências, Rio de Janeiro, 2006. ISSN 0103-9598. $91 \mathrm{p}$.

LEITE, M. E. Década de 70: A imigração e o caos urbano e Montes Claros. Iniciação a história, Montes Claros. V.2, n.1, p.130-141, jul.2003.

LEITE, M. E. ; PEREIRA, A. M. Metamorfoses do Espaço Intra-urbano de Montes Claros. 1. ed. Montes Claros: Editora da Unimontes, 2008. v. 1. 209 p.

MARKHAM, B. L., BARKER, J. L. Landsat MSS and TM post-calibration dynamic ranges, exoatmospheric reflectances and at-satellite temperatures, EOSAT Landsat Technical Notes, v. 1, p. 3-8, 1986.

SILVA, J. A. X. da. A pesquisa ambiental no Brasil: uma visão crítica. Cadernos de Geociências, Rio de Janeiro: IBGE, n. 14, p. 15-27, abr./jun. 1995.

SMITH, J.A.; LIN, T.L.; RANSON, K. The lambertian assumption and Landsat data. . Photogrammetric Engineering and Remote Sensing. v.46, n.9, p1183-1189, 1980.

TENEDÓRIO, J. A. Concepção de cartas de uso e evolução do solo por interpretação de fotografia aérea vertical. Almada: exemplo metodológico. Instituto Nacional de Investigação Científica. Centro de estudos de geografia e planejamento regional: FCSH-UNL, 1989. 80p.

TURNER, B. L. et al. Land use and land cover change (LUCC). Science/research plan. IGBP and HDP, 1995. 133p.

\section{Artigo recebido em 20/05/2013.}

Artigo aceito em 24/09/2013. 